\title{
Practices of Ritualization in a Dutch Hospice Setting
}

\author{
Kim van der Weegen ${ }^{1}$, Martin Hoondert ${ }^{2, * \mathbb{D}}$, Agnes van der Heide ${ }^{1}$ and \\ Madeleine Timmermann ${ }^{3}$ \\ 1 Department of Public Health, Erasmus MC, 3000 CA Rotterdam, The Netherlands; \\ a.vanderheide@erasmusmc.nl (A.v.d.H.) \\ 2 Department of Culture Studies, Tilburg School of Humanities and Digital Sciences, Tilburg University, \\ 5000 LE Tilburg, The Netherlands \\ 3 Groenhuysen Care Centre, 4702 ZB Roosendaal, The Netherlands; mtimmermann@groenhuysen.nl \\ * Correspondence: m.j.m.hoondert@tilburguniversity.edu
}

Received: 2 September 2020; Accepted: 30 October 2020; Published: 2 November 2020

\begin{abstract}
In this article, we explore rituals and ritualized care practices in a hospice in the Netherlands. The research is guided by two research questions. First, we want to know what kind of rituals and ritualized care practices are taking place in the hospice. Second, we aim to understand these practices from a cultural perspective, i.e., to what cultural values do these practices refer? We distinguish five types of ritual: (1) care practices in the morning; (2) meals; (3) care practices in the evening; (4) care practices in the dying phase; (5) a farewell ritual after a patient has died. Ritualization takes place in various degrees and forms, depending on changes in the state of liminality. Analysis of ritualized care practices shows that everyday care practices are enriched with non-instrumental elements that have a strong symbolic meaning, referring to the cultural value of the 'good death'.
\end{abstract}

Keywords: rituals; hospice; spirituality; cultural analysis; good death

\section{Introduction}

Rituals take place throughout our lives, but they become more visible during pivotal moments (Van Gennep 1960; Turner 1969). Being confronted with illness and death is a defining moment in life (Metcalf and Huntington 1991; Van Uden and Pieper 2012). Emotions and questions rise to the surface which cannot all be dealt with in a rational way. Rituals can help to provide a sense of meaning in situations we do not fully understand (Van Beek 2007).

Palliative care settings provide rich ground for rituals. When nothing can be done in terms of curing illness, rituals can provide an important source of meaning. The spectrum of rituals in palliative care settings is broad. It goes from more or less formalized rituals, such as a wake at the bedside of a dying person and religious rituals such as the anointment of the sick, to daily care practices with a ritual dimension, such as placing photos on the bedside table to make the dying person's social network visible. Practices with a ritual dimension, or ritualized acts, are practices that go beyond the mere instrumental or functional aim of the act. Those acts combine an instrumental and a symbolic dimension, referring to meaning(s) outside the act itself. 'Something' is added, which is useless from a medical perspective but meaningful to the persons involved (the healthcare professional and/or the patient). In the context of palliative care, there are numerous examples of ritualized acts that provide a sense of meaning to patients, families and healthcare professionals. Van der Geest (2005, p. 140) describes how the act of fluffing up a patient's pillow by a nurse is not just an instrumental act of making the patient more comfortable. This small and simple act also shows that the nurse is concerned with the patient, which in return might fill the patient with a positive feeling. The symbolic dimension of care is present in this seemingly small act. It exemplifies a caring relationship and shows that the patient is valuable to the nurse (Van der Weegen et al. 2019). 
In this article, we will explore rituals and ritualized care practices in a hospice in the Netherlands. The research is guided by two research questions. First, we want to know what kind of rituals and ritualized care practices are taking place in the hospice. Second, we aim at understanding these practices from a cultural perspective, i.e., to what cultural values do these practices refer? To answer the second research question, we will make use of the concept of death mentalities, as coined by the French historian Philippe Ariès (Ariès 1974; Jacobsen 2016), in which practices are linked to views of life and death.

\section{Conceptual Framework: Spirituality, Ritual and the Hospice as a Liminal Space}

\subsection{Spirituality}

Approaching care practices in a hospice from a ritual perspective fits the holistic approach of palliative care itself. From its beginnings, palliative care applies a holistic approach of care, meaning that a patient is approached from physical, psychological, social and spiritual perspectives. This becomes clear in, among other things, the definition of palliative care by the World Health Organization (WHO):

“[ $\ldots]$ an approach that improves the quality of life of patients and their families facing the problem associated with life-threatening illness, through the prevention and relief of suffering by means of early identification and impeccable assessment and treatment of pain and other problems, physical, psychosocial and spiritual." ${ }^{1}$

It is mainly the spiritual dimension of palliative care that leads us to pay attention to rituals and ritualized care practices. With this approach we follow, among others, ritual studies scholar Ronald Grimes, who explicitly links spirituality to ritual. In relation to the second research question of this article, we use a definition of spirituality which is, on the one hand, closely linked to the context of the research (palliative care and hospice care), and on the other hand, open and broad to include both religious and non-religious views on dying and death. For these reasons, we use the European consensus definition that was developed in the context of palliative care. According to this definition, spirituality is:

"[ ... ] the dynamic dimension of human life that relates to the way persons (individual and community) experience, express and/or seek meaning, purpose and transcendence, and the way they connect to the moment, to self, to others, to nature, to the significant and/or the sacred." (Nolan et al. 2011, p. 88)

This broad definition addresses both the individual and relational aspects of spirituality. In this study, we take on a relational approach of spirituality by looking at spirituality as a dimension that occurs in contacts between healthcare professionals and patients. Within this care relationship, meaning-making practices take place both implicitly and explicitly. This means we can find the spiritual dimension in everyday care practices.

\subsection{Ritual and Ritualization}

The focus on the spiritual dimension of everyday care practices led us to the field of ritual studies. So far, we have used the concepts of ritual and ritualization without defining them. In everyday language, the term ritual can have a negative connotation when it is used to describe repetitive and useless acts. We approach ritual as a cultural phenomenon and focus on the structures, meanings and functions of rituals (Post 2015). The following definition, developed by Paul Post, inspired by, among others, Tambiah and Grimes, corresponds to this approach:

1 https://www.who.int/cancer/palliative/definition/en/ (accessed 2 July 2020). 
"Ritual is a more or less repeatable sequence of action units which take on a symbolic dimension through formalization, stylization, and their situation in place and time. On the one hand, individuals and groups express their ideas and ideals, their mentalities and identities through these rituals, on the other hand the ritual actions shape, foster, and transform these ideas, mentalities and identities." (Post 2015, p. 7)

Characteristics that can be derived from this definition are repetition, enactment, symbolism, formalization and stylization. The second part of the definition focusses on possible functions of rituals, such as the expressive, social and ethical functions that rituals can have. Next to that, Post's definition shows that rituals are performative, as Stanley Tambiah already stated in his seminal 1979 article (Tambiah 1979).

Despite the use of a definition that states some of the key characteristics and functions of a ritual, it is not straightforward to identify an act as a ritual. Grimes (1990) states that when an act becomes dense with ritual characteristics, one can speak of ritualization or even a ritual. Whether an act is acknowledged as a ritual, is not a matter of definition but a cultural issue. Focusing on everyday practices in the field of palliative care, only a small number of activities can be formally labelled a ritual. However, there are many care practices which have ritual characteristics or functions. This field teaches us that even seemingly trivial and routine practices can become a source of meaning and spirituality, depending on the context and ways they are performed. This happens through processes of ritualization, which can be defined as consciously or unconsciously adding a ritual dimension to routine practices. On the surface, these practices might seem ordinary, but underneath, there are deeper symbolic meanings that go beyond the practice itself (Grimes 2014). We are often not aware of this. We act the way we act because it seems natural or appropriate in a situation (Bell 1997). Ritualization happens more often in situations in which we experience insecurity, a lack of control and discomfort. As such, the hospice is full of ritualized practices. Consequently, the focus within this article is placed on the processes of ritualization that take place in everyday care practices.

\subsection{The Hospice as a Liminal Space}

The dying process can be described as a rite of passage, a type of ritual that accompanies major life transitions. According to the rite of passage theory (Van Gennep 1960; Turner 1969), life transitions take place in a structured way and contain culture-specific values of the group, community or society that performs and witnesses the rite. During the rite of passage, separation takes place from former roles and identities and a person enters a state of liminality, a concept that we derive from Victor Turner who coined this quite complex concept as follows: "Liminal entities are neither here nor there; they are betwixt and between the positions assigned arrayed by law, custom, convention, and ceremonial." (Turner 1969, p. 95). This 'in-betweenness' is what happens when a person enters the palliative terminal phase of life, which is expressed and marked by all kinds of ritual acts. A liminal state is a state in which former roles and identities are (partially) abandoned and the new state is not in place yet. This liminal state allows for creativity and for situations to occur that otherwise would not be possible or appropriate (Thomassen 2016; Horváth et al. 2015). The relationships that are formed between the people involved, in this case the patients, family members and hospice staff, provide a base for transformation (Grimes 2014). In the context of the hospice, the physical transition to the hospice facility further intensifies the state of liminality. From their familiar environment, people now enter an unfamiliar physical place that is different and providing a break from the ordinary.

\section{Methods}

\subsection{Design}

Exploring the ritual dimension of care practices in a hospice facility, we applied a qualitative descriptive approach. Because ritualization is a natural part of human actions and interaction, including care practice, healthcare professionals are often not aware of it. To explore this tacit 
aspect of care practice, participant observation was chosen as one of the methods for data collection (see also Borgstrom 2018). In addition, in-depth semi-structured interviews were used to further clarify observations.

\subsection{Context}

Palliative care in the Netherlands is considered a generalist service; every nurse or doctor is expected to be able to provide palliative care. There are dedicated hospice services in the Netherlands consisting of in-patient professional driven hospices, in-patient volunteer driven hospices, a small amount of palliative care units within other healthcare institutions and hospice teams working in the community.

This study took place in an in-patient professional-driven hospice facility, referred to in the Netherlands as a 'high care hospice'. To obtain access to this hospice was quite easy, for one of the involved researchers (M.T.) is affiliated with the hospice as spiritual caregiver. This hospice facility has its own staff of healthcare professionals consisting of nurses, elderly care physicians and a spiritual counsellor. In addition, there is a team of volunteers supporting the hospice staff. The hospice consists of 16 private apartments. The hospice is located in a small city in the Netherlands, in the middle of a residential area next to the city center. The building is less than ten years old and was specifically designed as a hospice. The hospice is subtly placed in its surroundings and the simple façade is positioned some distance away from the street. The rest of the building is tucked away behind surrounding buildings that belong to a care facility. Visitors have to ring the doorbell and announce who they are before getting access. Even though the building is located in the middle of a city and community, it does not feel part of it. From the street, the building is hardly recognizable as a hospice and only in specific circumstances do people have access. From the inside of the hospice, there is hardly any contact with public life going on outside its walls. Pretty much all the spaces have large floor-to-ceiling windows but they look out over landscaped courtyards or the large garden, not on the surrounding streets.

Patients and family members entering the hospice are taken into the specific atmosphere of the hospice. An atmosphere that is dedicated to the experience of a good dying process. The different spaces at the hospice offer possibilities for privacy, togetherness, relaxation and contemplation. The spaces are decorated with warm materials and colors, symbolically referring to the peace, tranquility and even the strength of nature, and although patients and their families were taken into the specific atmosphere and structures of the hospice, staff recognized that each patient goes through the dying process in his or her own way.

\subsection{Participants}

All hospice staff, 14 nurses, 2 elderly care physicians and 1 spiritual counsellor, participated in the observational part of the study. Because the study focused on healthcare professionals, the hospice volunteers were not part of the study population. Four nurses served as key informants during observations. The number of patients participating in the study differed during the course of observations. Patients were eligible to participate if they were able and willing to provide verbal or written informed consent. About half the population of hospice patients was unable to meet this criterion. In total, ten patients and their relatives participated in the observational part of the study. In addition to the observations, five nurses, one physician, two patients and one relative participated in semi-structured interviews.

\subsection{Data Collection}

During October and November of 2017, researcher K.v.d.W. (who is both an anthropologist and a nurse) visited the hospice 18 times, during both day and evening shifts. A total of $120 \mathrm{~h}$ of observation were conducted. The degree of participation varied depending on the situation. Detailed field notes were written to cover the observations. The focus of the observations was interactions between 
healthcare professionals (nurses and physicians) and patients and their relatives. The researcher looked for explicit rituals and more-or-less implicit ritualized care practices taking place during the day. The researcher used the elements and qualities of ritual as described by Grimes (2014) as a model to describe and analyze practices from different angles and to identify specific meaning-making practices. Between observations, the researcher used techniques of informal interviewing to further discuss certain topics or situations with participants.

Five nurses, one physician, two patients and one relative participated in additional semi-structured interviews, conducted by researcher K.v.d.W. Each interview lasted, on average, $45 \mathrm{~min}$ and was audio recorded. Topic lists were developed by the research group (K.v.d.W., M.T., M.H. and A.v.d.H.) ${ }^{2}$ and based on themes from literature on death mentalities and themes from observations. The main topics were: the connection between spirituality (as defined above) and ritualization, experiences with meaning-making practices in everyday care situations and views on life and death.

\subsection{Data Analysis}

Detailed anonymized field notes of observations were analyzed deductively, by researchers K.v.d.W. and M.H., using a theoretical and hermeneutical framework for studying ritual, based on models from Ronald Grimes (2014) and Catherine Bell (Bell 1997). The framework consists of elements, qualities and functions that can make up a ritual. Different types of practices taking place during interactions between doctors/nurses and patients/relatives were analyzed by identifying if and how ritual elements, characteristics and functions were present in the situation. See Table 1 for the framework for analysis.

Table 1. Framework for analysis.

\begin{tabular}{|c|c|}
\hline Actions & Which actions take place in this situation and why are they deemed appropriate? \\
\hline Qualities & $\begin{array}{l}\text { Which ritual qualities can be applied to this situation? (e.g., enactment, stylization, } \\
\text { repetitive, standardized, meaning, multi-layered, symbolic and deliberate) }\end{array}$ \\
\hline Actors & Who ritualizes in this situation and to whom is it directed? \\
\hline Functions & $\begin{array}{l}\text { What is the function of ritualization in this situation? (e.g., discharge function, ethical } \\
\text { function, prophylactic function, expressive function, social function and recreational function) }\end{array}$ \\
\hline Place, objects, time & What are the roles of place, objects and time in this situation? \\
\hline Category & $\begin{array}{l}\text { Is there a ritual category applicable to this situation? (e.g., rites of passage, calendar rites, } \\
\text { rites of exchange and communion, rites of affliction and healing and feasts and festivals) }\end{array}$ \\
\hline
\end{tabular}

Inductive thematic analysis was used to analyze the anonymized interview transcripts by researcher K.v.d.W. Open coding was the first step in the process of analysis. The initial codes were then clustered into groups. Themes were then ascribed to the different clusters of codes. The principle of constant comparison was used during the process of analysis. The process of analysis was monitored by researchers M.T., M.H. and A.v.d.H. by periodically discussing and reflecting on the evolving codes and themes.

\section{Findings}

\subsection{Ritualization of Care Practices}

Observations showed that ritualization took place during all types of care practices at the hospice. The repertoire of ritualized care practices in the hospice consists of (1) care practices in the morning,

2 The research group consisted of four members. K.v.d.W. has a background in anthropology and is nurse, M.T. is spiritual caregiver in the hospice that functioned as site of research, M.H. is a ritual studies scholar and A.v.d.H. is professor in medical decision-making and care at the end of life. 
such as washing, dressing and providing medicines; (2) meals; (3) care practices in the evening, such as undressing, putting on pajamas and putting to bed; (4) care practices in the dying phase, such as washing and putting on clean clothes; (5) a farewell ritual after a patient has died. This last ritual differs from the other ones because, instead of focusing on the patient, it focuses on both the bereaved and the care professionals who took care of the patient. The farewell ritual concludes the period of the stay in the hospice.

Analysis of the various ritualized care practices in the hospice context shows that ritualization takes place on a continuum. This means that ritualization takes place in various degrees and forms depending on changes in the dying process. We saw lower degrees of ritualization when the situation of the patient was relatively stable. This was the case with patients staying at the hospice for a longer period of time because their health situation stayed the same or deteriorated very slowly. In these situations, ritualization was directed at coping with the liminal situation of being in the hospice. This often happened by creating small moments of significance during bathing moments, meals (see Brumberg-Kraus 2020), bed time and during the night.

High degrees of ritualization were found on the other side of the continuum, when the situation of the patient was unstable because transition to death came near. This was the case with patients who entered the dying phase. In these situations, ritualization was directed to preparing for and assisting in a good transition to death. In the following, we will describe, analyze and evaluate two ritualized care practices, on both ends of the continuum.

\subsection{Small Moments of Significance}

Mrs. Van Beek had been staying at the hospice for quite a number of weeks. She was an active woman until recently. Mrs. Van Beek is now immobile and spends her days in a wheelchair and in bed, sleeping most of the time. Her eyesight is bad so activities to occupy herself are difficult. Despite regular visits from family and friends, she often expresses that she feels lonely and that every day feels the same. During day-to-day practices at the hospice, nurses take this into account. They engage in contact with Mrs. Van Beek as often as possible, mostly through the senses of touch, smell and taste. Nurses pay specific attention to the bed bath Mrs. Van Beek gets in the mornings. She enjoys the proximity of the nurses in this situation and being pampered. The bed bath was given according to the existing nursing protocols and guidelines. The nurse, however, added her own elements to this situation. She brought in heated towels to cover Mrs. Van Beek during the process of washing and getting dressed. The nurse indicated that she found it important to give her patients a little bit of a wellness moment. Another essential element of the bed bath was to attentively massage Mrs. Van Beek using her personal marigold oil. The sensation and smell brought about positive associations and feelings, and every time, Mrs. Van Beek would remark on this. The nurse always ended the bathing moment by applying Mrs. Van Beek's favorite perfume, and again, she would comment how much she loved the smell.

The case of Mrs. Van Beek exemplifies how patients at the hospice can experience the state of liminality. She entered the hospice knowing that she was going to die but her health situation has remained the same for weeks now. Because she is too weak to do anything, her days are pretty much the same. In this relatively stable state of liminality, degrees of ritualization are low.

The routine bathing moment stands out from the ordinary through the stylized and deliberate use of warmth, massage and smell. The acts are symbolic because they served to connect to Mrs. Van Beek and to acknowledge her value as a person. This was both meaningful to the nurse and to Mrs. Van Beek. The marigold oil and perfume were symbolic objects because they represented positive associations with home and the life she used to live, which are meaningful to Mrs. Van Beek.

In this situation, ritualization had a recreational function by providing a small moment of significance that stands out in a day in which there was little to look forward to. These small moments of joy are her anchors during the day that provide structure and meaning. In that way, these practices could also be prophylactic, and in a small way, they might help Mrs. Van Beek cope with her situation. 
To the nurse, ritualization also had an expressive function as a way of expressing the value that she attributes to Mrs. Van Beek as a person.

As insignificant as these small, ritualized activities might appear, they create structure, meaning and value in the days of the patients and are a source of human connectedness, compassion and acknowledgment.

\subsection{Nearing Death: Intensification of Ritualization}

Mr. Bakker was only a few days at the hospice when his condition deteriorated rapidly and palliative sedation was started. His family was very involved and stayed with him most of the day. During the night, they went home to get some rest. At the start of the morning shift, one of the nurses went to care for Mr. Bakker. She explained that she always tried to attend to patients in the dying phase first, before the family would come, so she would not have to disturb them later. Mr. Bakker was in the final phases of life but the nurse felt it was important to give him a quick bed bath to freshen up. She did not want to add any stress or discomfort to the situation so she only washed the body parts she could reach without having to manipulate the body too much. The nurse noticed that his shirt was wet from sweating and doubted whether she should change it. After thinking about it, she decided to change the shirt. Mr. Bakker opened his eyes and made noises breathing in the process of changing the shirt, signaling discomfort, so the nurse tried to work as subtly as she could. Eventually, the nurse turned him on his side and positioned him comfortably using pillows. On the pillow, the nurse placed a towel to collect the occasional mucus escaping from the mouth. After caring for Mr. Bakker, the nurse paid close attention to tidying up the room. She placed the bed in the middle of the room and a chair next to the bed. The bedside table, decorated with pictures of family, was now located on the opposite side of the bed so she relocated it facing towards Mr. Bakker. On the dresser the nurse saw a bracelet Mr. Bakker used to wear and a rosary; she placed both in front of the pictures on the bedside table. When asked why she did that, she could not really explain. She stated that she always does those things because it makes her feel good to do so. She also stressed that she would not place items in the bed with the patient unless she is sure a patient has a strong connection to the items.

This situation is an example in which the state of liminality is changing because the transition to death is near. The experienced intensity and importance of the situation is expressed and marked by high degrees of ritualization and multiple layers of interpretation. In this situation, the nurse enacts the hospice ideal of a good death. In a stylized way, she washes away traces of bodily distress, making sure the client appears to the family as clean and calm. She deliberately places the bedside table with the pictures, bracelet and rosary near the patient. These objects are symbols of what is important to the patient, and by placing them, the nurse acknowledges that. By paying attention to the placement of objects in the room, she also expresses her acknowledgment of Mr. Bakker as a unique person, not just a patient who can be anybody. To a certain degree, the situation is also repetitive and standardized. Although the nurse tailors her care to the needs of this individual person, she also acts in a way that is common for healthcare professionals in the dying phase. They do not simply act this way because it is routine but because it is considered meaningful to both themselves and to the patient and his family. The practice of giving the patient a superficial bed bath in the dying phase is not purely instrumental but mostly symbolic. It is about respecting the integrity of the body, the value that is attributed to the person and the life he lived and the value that is attributed to the dying process.

Ritualization in this situation has a prophylactic function-it helps both the nurse and the family to cope with the situation. It is a way for the nurse to deal with the imminent loss of the patient. She also attempts to help the family cope by making the patient appear as dignified as possible, clean and seemingly calm. Ritualization is also expressive in this situation. Through her actions, the nurse communicates that she values Mr. Bakker as a person and values his process towards a good death. 


\section{Discussion: Ritualizing Everyday Care Practices}

The two examples show that everyday care practices are enriched with non-instrumental elements that have a strong symbolic value. The way a practice is performed, both following the protocol and adding personal elements, adds to the spiritual dimension of palliative care. On the one hand, this is just 'good and professional care', while on the other, it turns this specific care practice into a 'sacred' moment in time. We use the word 'sacred' here in accordance with Gordon Lynch's cultural-sociological approach of the sacred, referring to the moral or guiding values on which people build their lives (Lynch 2012). What is sacred to us is set apart because it transcends the physical reality of everyday life. The moral or guiding values that we hold sacred seem natural and fixed, so we are often not aware of them. However, they are products of culture and history that are constantly being negotiated and recreated. The main sacred, moral value that is both produced and expressed in the ritualized care practices is the value of the 'good death'. The concept of 'good death' is closely linked to the hospice movement as initiated by Cicely Saunders as of 1967 (Milicevic 2002). Within the healthcare community and, more specifically, in hospice and palliative care, there has been discussion of the concept of a good death (Gawande 2015; Raisio et al. 2015). According to an Institute of Medicine report (USA), a good death is one that is "free from avoidable distress and suffering for patient, family, and caregivers, in general accord with the patient's and family's wishes, and reasonably consistent with clinical, cultural, and ethical standards." (Field and Cassel 1997, p. 24). However, as Raisio et al. state, "a good death can be considered a 'wicked issue' — that is, a highly divisive and complex matter on which no consensus is evident." (Raisio et al. 2015, p. 159).

The concept of the good death can be linked to the history of cultural attitudes towards death, as coined by Philippe Ariès (Ariès 1974, 1983). Ariès made a distinction between pre-modern and modern conceptions of the good death, but actually, this is too simple. Both conceptions are part of modern day reality and coexist next to each other. The 'pre-modern' conception of a good death focused on the religious dimension: being at peace with God at the moment of death. This way of thinking about the dying process is still an issue, even though it is not phrased in religious terms. In literature, we see that 'being at peace' with the impending death, with family, friends and oneself is the norm according to many palliative care professionals and patients (Coward and Stajduhar 2012, p. 141; Bramadat et al. 2013, p. 107).

The 'modern' conception of a good death came out of advances in medical science. As the dying process became increasingly medicalized, the imperative became to avoid suffering and pain and to postpone death. Ariès coined this attitude as the taboo on death or the denial of death (see also Becker 1973). At the same time, a new attitude towards death emerged of which the hospice movement is part. The keyword in this new attitude is 'control'. In the hospice movement, this has been translated in controlling the suffering and helping people to die in dignity and without pain. This conceptualization of a good death, however, is complex and contested. A good death does not refer to a fixed moment in time but should be seen as a complex set of relations and preparations (McNamara et al. 1994). It does involve a range of attributes, such as being comfortable, a sense of closure, recognition of the value of the dying person, honoring of beliefs and values and optimizing relationships (Kehl 2006). These characteristics or attributes of the good death are made visible in the ritualized care practices as described and analyzed above. Palliative care professionals are trying to hide the 'ugliness' of death, at least from the dying person's family perspective, and to make the dying process as comfortable as possible.

\section{Conclusions}

In this study, we explored rituals and ritualized care practices in a hospice in the Netherlands. The exploration of these practices led to two types of categorization: the first one is more or less practical, referring to the moments of the day and the character of the acts; the second one is linked to the health condition of the patient and the impending death.

We have brought the exploration of rituals and ritualizing within the broader framework of the spiritual dimension of palliative care, using a general and broad definition of spirituality referring 
to notions of meaning, purpose and transcendence, and the way people connect to the moment, to self, to others, to nature and to the significant and/or the sacred. In ritualized care practices, meaning and purpose are linked to the concept of the good death. Hospice staff recognize the major life transition their patients and families are going through when they enter the hospice. Although the care professionals do not mention the concept of the good death, the analysis from a ritual and cultural perspective has shown that this value guides the everyday care practices and the professionals' approach of the patients.

Author Contributions: Conceptualization, K.v.d.W. and M.H.; Methodology, K.v.d.W. and M.H.; Participant Observation and Interviews: K.v.d.W.; Formal Analysis, K.v.d.W., M.H., M.T., and A.v.d.H.; Writing-Original Draft Preparation, K.v.d.W. and M.H.; Writing-Review \& Editing, M.H.; Supervision, A.v.d.H. and M.T.; Funding Acquisition, M.T., A.v.d.H., and M.H. All authors have read and agreed to the published version of the manuscript.

Funding: The authors obtained a grant from the Netherlands Organisation for Health Research and Development (ZonMw) to conduct the research project titled 'Spiritual care and rituals in primary care'. The project is registered under the Dutch title 'Spirituele zorg en rituelen in de eerste lijn', with the corresponding Project Number: 80-84400-98-335.

Acknowledgments: We thank the two anonymous reviewers for their valuable suggestions to improve the first draft of this article.

Conflicts of Interest: The authors declare no conflict of interest.

Ethics Statement: Approval for this study was granted by the medical ethics committee of the Erasmus Medical Centre (Rotterdam, the Netherlands) on August 18th 2017.

\section{References}

Ariès, Philippe. 1974. Western Attitudes toward Death: From the Middle Ages to the Present. Baltimore: John Hopkins University Press.

Ariès, Philippe. 1983. The Hour of Our Death. Harmondsworth: Penguin.

Becker, Ernest. 1973. The Denial of Death. New York: The Free Press.

Bell, Catherine. 1997. Ritual: Perspectives and Dimensions. New York: Oxford University Press.

Borgstrom, Erica. 2018. Using an ethnographic approach to study end-of-life care: Reflections from research encounters in England. In Ethnographies and Health: Reflections on Empirical and Methodological Entanglements. Edited by Emma Garnett, Joanna Reynolds and Sarah Milton. London: Palgrave Macmillan, pp. 67-83.

Bramadat, Paul, Harold G. Coward, and Kelli I. Stajduhar. 2013. Spirituality in Hospice Palliative Care. Albany: State University of New York Press.

Brumberg-Kraus, Jonathan. 2020. The Role of Ritual in Eating. In Handbook of Eating and Drinking: Interdisciplinary Perspectives. Edited by Herbert L. Meiselman. Cham: Springer (E-book), pp. 333-48.

Coward, Harold G., and Kelli I. Stajduhar. 2012. Religious Understandings of a Good Death in Hospice Palliative Care. Albany: State University of New York Press.

Field, Marilyn J., and Christine K. Cassel. 1997. Approaching Death: Improving Care at the End of Life. Washington: National Academy Press.

Gawande, Atul. 2015. Being Mortal. London: Wellcome Collection.

Grimes, Ronald L. 1990. Ritual Criticism: Case Studies in Its Practice, Essays on Its Theory. Studies in Comparative Religion. Columbia: University of South Carolina Press.

Grimes, Ronald L. 2014. The Craft of Ritual Studies. Oxford: Oxford University Press.

Horváth, Ágnes, Bjørn Thomassen, and Harald Wydra. 2015. Breaking Boundaries: Varieties of Liminality. New York: Berghahn Books.

Jacobsen, Michael. 2016. "Spectacular Death"-Proposing a New Fifth Phase to Philippe Ariès's Admirable History of Death. Humanities 5: 19. [CrossRef]

Kehl, Karen. 2006. Moving Toward Peace: An Analysis of the Concept of a Good Death. American Journal of Hospice and Palliative Medicine 23: 277-86. [CrossRef]

Lynch, Gordon. 2012. On the Sacred. Durham: Acumen.

McNamara, Beverley, Charles Waddell, and Margaret Colvin. 1994. The institutionalization of the good death. Social Science \& Medicine 39: 1501-8. [CrossRef]

Metcalf, Peter, and Richard Huntington. 1991. Celebrations of Death: The Anthropology of Mortuary Ritual, 2 nd ed. Cambridge: Cambridge University Press. 
Milicevic, Natasa. 2002. The hospice movement: History and current worldwide situation. Archive of Oncology 10: 29-32. [CrossRef]

Nolan, S., P. Saltmarsh, and C. Leget. 2011. Spiritual care in palliative care: Working towards an EAPC Task Force. European Journal of Palliative Care 18: 86-89.

Post, Paul. 2015. Ritual Studies. Oxford Research Encyclopedia of Religion. [CrossRef]

Raisio, H., P. Vartiainen, and A. Jekunen. 2015. Defining a Good Death: A deliberative democratic view. Journal of Palliative Care 31: 158-65. [CrossRef]

Tambiah, Stanley. 1979. A Performative Approach to Ritual. Proceedings of the British Academy 65: 113-69.

Thomassen, Bjørn. 2016. Liminality and the Modern: Living Through the in-Between. London: Routledge.

Turner, Victor. 1969. The Ritual Process: Structure and Anti-Structure. Ithaca: Cornell University Press.

Van Beek, Wouter. 2007. De Rite Is Rond. Betekenis en Boodschap van Het Ongewone. Tilburg: Universiteit van Tilburg.

Van der Geest, Sjaak. 2005. 'Sacraments' in the Hospital: Exploring the Magic and Religion of Recovery. Anthropology \& Medicine 12: 135-50. [CrossRef]

Van der Weegen, Kim, Martin Hoondert, Madeleine Timmermann, and Agnes van der Heide. 2019. Ritualization as Alternative Approach to the Spiritual Dimension of Palliative Care: A Concept Analysis. Journal of Religion and Health 58: 2036-46. [CrossRef] [PubMed]

Van Gennep, Arnold. 1960. The Rites of Passage. Chicago: University of Chicago Press.

Van Uden, Rien, and Jos Pieper. 2012. Ritualiteit Tussen Heil en Heling. Tilburg: KSGV.

Publisher's Note: MDPI stays neutral with regard to jurisdictional claims in published maps and institutional affiliations.

(C) 2020 by the authors. Licensee MDPI, Basel, Switzerland. This article is an open access article distributed under the terms and conditions of the Creative Commons Attribution (CC BY) license (http://creativecommons.org/licenses/by/4.0/). 